\title{
The Control of Hyperphosphatemia in Renal Failure: Between Vascular Calcification and Inflammation
}

\author{
Mario Cozzolino \\ Renal Division, S. Paolo Hospital, University of Milan, Milan, Italy
}

In this issue of Blood Purification, I read with interest the article by Hauser et al. [1] on the effects of the aluminum- and calcium-free phosphate binder sevelamer carbonate on reducing the levels of tumor necrosis factor $\alpha$ and endotoxin in an experimental model of uremia. The authors' results support one of the potential mechanisms involved in vascular calcification (VC): the role of phosphate in regulating arterial mineralization, in a manner 'similar' to bone formation.

I have really found the manuscript of interest, and I would like to discuss why these results may be important from the clinical point of view, with special attention to chronic kidney disease (CKD) patients.

Accelerated atherosclerosis and $\mathrm{VC}$ play a central role in the pathogenesis of cardiovascular disease in CKD patients. Mineral metabolism disorders and increased serum calcium-phosphate product have recently been investigated as inducing factors in cardiovascular calcification [2]. In fact, cardiovascular disease in renal failure appears greatly associated with alterations of bone metabolism. Recently, the treatment of hyperphosphatemia in CKD patients changed from either calcium- or aluminum-based phosphate binders to new calcium- and aluminum-free phosphate binders, such as sevelamer carbonate and lanthanum carbonate. Therefore, control of serum phosphate in CKD patients becomes crucial in preventing increases in calcium-phosphate product, secondary hyperparathyroidism and ultimately VC.

CKD patients develop extensive medial calcification, which contributes to higher cardiovascular morbidity and mortality [2]. In addition to elderly age, male gender, inflammation, mineral metabolism abnormalities and diabetes, new potential factors are emerging which help to better understand the pathogenesis of VC in CKD. In the last decade, both new molecular and cellular mechanisms have been investigated in the pathophysiology of secondary hyperparathyroidism and VC in CKD [3-5]. Accordingly, different bone-related proteins are now certified for their capacity of promoting or inhibiting the process of extraskeletal calcification [6, 7]. The pathogenesis of phosphate-induced VC has been investigated in depth [8], and different in vitro studies have demonstrated that high phosphate concentration in growth media causes VC by a specific activation of the core-binding factor $\alpha_{1}$ (Cbfa1), an osteoblast-specific gene that regulates the expression of several bone morphogenic proteins [9]. In CKD, the expression of these proteins was also caused by serum from uremic patients with normal serum phosphate [10]. Interestingly, an increased expression of both Cbfal and osteopontin has been shown in calcified arteries from CKD patients [11]. Clearly, these data suggest that VC is an active process. The cellular formation of a

\section{KARGER}

Fax +4161306 1234 E-Mail karger@karger.ch www.karger.com
(C) 2010 S. Karger AG, Basel

0253-5068/10/0303-0159\$26.00/0

Accessible online at:

www.karger.com/bpu
Mario Cozzolino, $\mathrm{MD}, \mathrm{PhD}$

Renal Division, S. Paolo Hospital, University of Milan

Via A. di Rudinì, 8

IT-20142 Milan (Italy)

Tel. +39 028184 4381, Fax +39 028912 9989, E-Mail mariocozzolino@ hotmail.com 
bone-like structure in calcified vessel walls indicates that the uremic environment and elevations in serum phosphate levels may be regulating factors. Considering the concentration product of serum calcium and phosphate, physicochemical crystallization would occur continuously if it were not inhibited by specific macromolecules.

The chronic 'nonspecific' microinflammation, a typical condition of CKD, has been investigated as a wellrecognized risk factor involved in the pathogenesis of accelerated atherosclerosis and VC. In fact, end-stage renal disease patients with either VC or valvular calcification may have higher serum levels of different markers of inflammation, such as C-reactive protein, tumor necrosis factor $\alpha$ or interleukin 6 [12].

Switching from experimental studies to the clinical setting, it is a well-accepted concept that optimizing therapy to reduce hyperphosphatemia is crucial for minimizing extraskeletal calcification in uremic patients. Recently, sevelamer carbonate, an improved, buffered form of sevelamer hydrochloride, has been studied in patients with CKD not on dialysis [13] and under dialysis treat- ment [14]. Serum bicarbonate levels decreased with sevelamer hydrochloride, but both sevelamer carbonate and sevelamer hydrochloride demonstrated efficacy in controlling serum phosphorus. Sevelamer carbonate may have advantages over sevelamer hydrochloride in the treatment of hyperphosphatemia in both CKD and hemodialysis patients, where previously bicarbonate levels were shown to be reduced when switching from calciumbased binders to sevelamer hydrochloride [15].

In conclusion, current evidence suggests that bone mineral derangements represent a plausible target for therapy. Indeed, careful evaluation of phosphate binder choice seems to improve survival in hemodialysis patients. Although promising, these results are mainly based on retrospective and observational data, and more randomized clinical trials are needed to confirm these findings in CKD patients. Furthermore, survival data from newer non-calcium- and non-aluminum-containing phosphate binders are awaited to shed further light on this complex syndrome and hopefully ameliorate survival in CKD.

\section{References}

1 Hauser AB, Azevedo IRF, Gonçalves SM, Stinghen A, Aita C, Pecoits-Filho R: Sevelamer carbonate reduces inflammation and endotoxemia in an animal model of uremia. Blood Purif 2010;30:153-158.

-2 Cozzolino M, Brancaccio D, Gallieni M, Slatopolsky E: Pathogenesis of vascular calcification in chronic kidney disease. Kidney Int 2005;68:429-436.

$\checkmark 3$ Messa PG, Cerutti R, Brezzi B, et al: Calcium and phosphate control by dialysis treatments. Blood Purif 2009;27:360-368.

$\checkmark 4$ Cozzolino M, Ciceri P, Volpi EM, et al: Pathophysiology of calcium and phosphate metabolism impairment in chronic kidney disease. Blood Purif 2009;27:338-344.

5 Cozzolino M, Mazzaferro S, Pugliese F, Brancaccio D: Vascular calcification and uremia: what do we know? Am J Nephrol 2008;28:339-346

6 Wei T, Wang M, Wang M, Gan LY, Li X: Relationship of sRANKL level and vascular calcification score to cardiovascular events in maintenance hemodialysis patients. Blood Purif 2009;28:342-345.
Cozzolino M: Emerging roles for osteoprotegerin and receptor activator of nuclear factor $\kappa \mathrm{B}$ in the vascular system. Blood Purif 2009; 28:346-347.

$\checkmark 8$ Jono S, McKee MD, Murry CE, et al: Phosphate regulation of vascular smooth muscle cell calcification. Circ Res 2000;87:E10-E17.

$\checkmark 9$ Ducy P, Zhang R, Geoffroy V, et al: Osf2/ Cbfa1: a transcriptional activator of osteoblast differentiation. Cell 1997;89:747-754.

10 Chen NX, O’Neill KD, Duan D, Moe SM: Phosphorus and uremic serum up-regulate osteopontin expression in vascular smooth muscle cells. Kidney Int 2002;62:1724-1731.

-11 Moe SM, Duan D, Doehle BP, et al: Uremia induces the osteoblast differentiation factor Cbfal in human blood vessels. Kidney Int 2003;63:1003-1011.
12 Wang AY, Lam CW, Wang M, et al: Associations of serum fetuin-A with malnutrition, inflammation, atherosclerosis and valvular calcification syndrome and outcome in peritoneal dialysis patients. Nephrol Dial Transplant 2005;20:1676-1685.

13 Delmez J, Block G, Robertson J, et al: A randomized, double-blind, crossover design study of sevelamer hydrochloride and sevelamer carbonate in patients on hemodialysis. Clin Nephrol 2007;68:386-391.

14 Gallieni M, Cozzolino M, Brancaccio D: Transient decrease of serum bicarbonate levels with sevelamer hydrochloride as the phosphate binder. Kidney Int 2000;57:17761777.

15 Hutchison AJ, Barnett ME, Krause RJ, Siami GA, Lanthanum Carbonate Study Group: Lanthanum carbonate treatment, for up to 6 years, is not associated with adverse effects on the liver in patients with chronic kidney disease stage 5 receiving hemodialysis. Clin Nephrol 2009;71:286-289. 